\title{
Anabaena xisF gene encodes a developmentally regulated site-specific recombinase
}

\author{
Claudio D. Carrasco, K.S. Ramaswamy, T.S. Ramasubramanian, and James W. Golden \\ Department of Biology, Texas A\&M University, College Station, Texas 77843-3258 USA
}

\begin{abstract}
Two DNA elements are excised from the chromosome during Anabaena heterocyst differentiation. We have identified the gene $x i s F$ which encodes the site-specific recombinase responsible for the excision of a 55-kb element from within the $f d x N$ gene. The cloned $x i s F$ gene is sufficient to cause site-specific rearrangement of an artificial substrate in Escherichia coli. Inactivation of $x i s F$ in the Anabaena chromosome prevents excision of the $f d x N$ element and growth in nitrogen-deficient medium but does not alter the development of heterocysts. Forced transcription of xis $F$ in vegetative cells did not result in excision of the $f d x N$ element, suggesting that other factors may be involved in cell-type specificity. The predicted XisF protein shows significant similarity to the Bacillus subtilis SpoIVCA recombinase.
\end{abstract}

[Key Words: Anabaena; cyanobacteria; heterocyst; nitrogen fixation; recombinase; DNA rearrangement]

Received October 12, 1993; revised version accepted November 12, 1993.

Programmed DNA rearrangements occur in both eukaryotes and prokaryotes. Several examples of genome rearrangements associated with development in eukaryotes are known and include the immunoglobulin and T-cell receptor genes in the vertebrate immune system (Gellert 1992; Oettinger 1992); chromatin diminution in nematodes (Tobler et al. 1992); formation of the macronucleus in hypotrichous ciliates (Prescott 1992); and yeast mating-type switching (Haber 1992). In prokaryotes, developmentally regulated genome rearrangements have been found in two organisms (Haselkorn 1992). During Bacillus subtilis sporulation, a $42-\mathrm{kb}$ element named skin is deleted from within the $\operatorname{sig} K$ gene in the terminally differentiating mother cell (Kunkel et al. 1990). The rearrangement is the result of site-specific recombination and requires the spoIVCA gene, which is located on the excised element and which shows homology to the $\operatorname{Tn} 3$ resolvase family of site-specific recombinases (Kunkel et al. 1990; Sato et al. 1990; Stark et al. 1992). During heterocyst differentiation in Anabaena sp. strain PCC 7120, at least two DNA rearrangements occur that involve the deletion of DNA elements from the chromosome by conservative site-specific recombination (Golden et al. 1985, 1987).

Anabaena sp. strain PCC 7120 is a filamentous, heterocystous cyanobacterium capable of oxygen-evolving photosynthesis and nitrogen fixation. Development of the nitrogen-fixing heterocysts is repressed in the presence of a source of combined nitrogen in the environment. Under nitrogen-limiting conditions Anabaena grows as a simple multicellular organism composed of two interdependent cell types: vegetative cells and het- erocysts. Heterocysts differentiate from about every tenth vegetative cell along a filament producing a onedimensional semiregular pattern (Wolk 1989). Heterocysts are highly specialized, terminally differentiated cells that reduce atmospheric dinitrogen to ammonia (Wolk 1982). The fixed nitrogen is exported to neighboring vegetative cells as glutamine, and in exchange, heterocysts are provided with carbohydrate products of photosynthesis.

Heterocyst differentiation in PCC 7120 is accompanied by at least two developmentally regulated DNA rearrangements that affect the nifD and the $f d x N$ genes. Both rearrangements occur during the late stages of differentiation, at about the same time that the nitrogenfixation genes begin to be transcribed (Golden et al. 1985, 1991). The nifD rearrangement is the excision of an 11 $\mathrm{kb}$ element from within the nifD open reading frame and allows for the formation of the complete nifD gene and the correct expression of the nifHDK operon (Haselkorn et al. 1986). Excision occurs by site-specific recombination between two 11-bp direct repeats that border the element and requires the xis $A$ gene, which is present on the element (Lammers et al. 1986; Golden and Wiest 1988; Brusca et al. 1990). xisA is necessary and sufficient to cause rearrangement of the nifD element in PCC 7120 and of an artificial substrate in E. coli. However, XisA does not show significant similarity to either the integrase or resolvase family of site-specific recombinases (Stark et al. 1992).

The $f d x N$ rearrangement is the excision of a $55-\mathrm{kb}$ element from within the $f d x N$ open reading frame by conservative site-specific recombination between 5 -bp di- 
rectly repeated sequences (Golden et al. 1987, 1988; Mulligan et al. 1988). Excision of the $f d x N$ element results in the formation of the $f d x N$ gene and the nifB-fdxN-nifSnif $U$ operon on the heterocyst chromosome (Mulligan and Haselkorn 1989).

Although the nifD and $f d x N$ elements share some general characteristics, they are not directly related to each other. The elements do not show cross-hybridization using low-stringency Southern analysis (C.D. Carrasco and J.W. Golden, in prep.). The two elements are not always found together in cyanobacterial strains. Of several $A n$ abaena and Nostoc strains examined using low-stringency hybridizations, three strains contained both elements while five others contained only the nifD element (C.D. Carrasco and J.W. Golden, in prep.). The repeated sequences involved in site-specific recombination differ for the two elements (Golden et al. 1987), and the xisA gene on the nifD element is not required for excision of the $f d x N$ element in heterocysts /Golden and Wiest 1988). Under certain microaerobic heterocyst-inducing conditions, the $f d x N$ element is excised from the chromosome while the nifD element is not (Golden et al. 1988). These observations indicate that at least some of the genes required for the developmentally regulated excision of the $f d x N$ element are specific for that element.

We report the identification of the xisF gene, which is present on the $f d x N$ element. $x i s F$ is shown to be required for excision of the $f d x N$ element from the heterocyst chromosome. xisF is sufficient to cause rearrangement of an artificial substrate plasmid in $E$. coli, but forced xis $F$ expression in PCC 7120 vegetative cells does not cause excision of the $f d x N$ element, suggesting that other factors are required for cell-type specificity. XisF appears to be homologous to the Bacillus subtilis developmentally regulated recombinase SpoIVCA.

\section{Results}

\section{Identification of the xisF gene}

The 11-kb nif $D$ element and the $55-\mathrm{kb} f d x N$ element are located near each other around map position $1.7 \mathrm{Mb} / \mathrm{Ku}$ ritz et al. 1993) on the PCC 7120 vegetative cell chromosome in a region containing several nif operons (Fig. 1A). The $f d x N$ element interrupts the $f d x N$ open reading frame in the nifB-fdxN-nifS-nifU operon. One of our approaches to identify the gene(s) required for excision of the $f d x N$ element was to determine the DNA sequence of the ends of the element. We suspected that like most other mobile genetic elements, the gene encoding the site-specific recombinase was likely to be located near one of the recombination sites. Sequence analysis showed a large open reading frame located near the nifSproximal border of the $f d x N$ element, which we have named xisF (Fig. 1A). Figure 1B shows 1700 bp of DNA sequence that contains $x i s F$. The $x i s F$ start codon is 47 bp from the 5-bp sequence involved in site-specific recombination that marks the border of the element. The 1545-bp xis $F$ open reading frame could encode a 515amino-acid polypeptide with a calculated molecular weight of 58,473 and a pI of 9.83 .
We were unable to detect $x i s F$ transcription by Northern analysis. We suspect that xisF is transcribed at low levels and probably only transiently during heterocyst differentiation.

\section{Sequence similarity between XisF and SpoIVCA}

Comparison of the predicted XisF amino acid sequence with data bases revealed similarities with the resolvase family of site-specific recombinases. Members of this family include the resolvases from a number of transposons including $\operatorname{Tn} 3$, and the invertases related to Hin and Gin (Stark et al. 1992). All but one member of this class of proteins are $\sim 20 \mathrm{kD}$ in size. The exception is the B. subtilis SpoIVCA recombinase, which contains 500 amino acids and has a calculated molecular weight of 57,481 (Sato et al. 1990). The spoIVCA gene is required for excision of the $42-\mathrm{kb}$ skin element in mother cells during $B$. subtilis sporulation. The amino acid sequences of XisF and SpoIVCA can be aligned along their entire length and show $49 \%$ similarity and $27 \%$ identity (Fig. 2). The amino-terminal region of SpoIVCA is homologous with the resolvase family of site-specific recombinases (Sato et al. 1990). An analysis using the GCG LINEUP program showed that the amino-terminal region of XisF can be aligned with this family of recombinases and that several amino acid positions are highly conserved in all of the proteins (Fig. 2).

Although XisF and SpoIVCA show significant similarity, their target sequences are quite different from each other (Golden et al. 1987; Stragier et al. 1989). SpoIVCA has been shown to bind to sequences flanking the skin element recombination sites and to cause DNA bending (Popham and Stragier 1992). It was also shown that a truncated form of SpoIVCA that contains only the amino-terminal region corresponding to the resolvase family retains its ability to bind DNA but is unable to carry out the skin excision in vivo. XisF could be expected to have similar properties.

\section{Rearrangement of pIG1A in E. coli}

The location of the $x i s F$ gene adjacent to one border of the $f d x N$ element and the sequence similarity between $\mathrm{XisF}$ and other site-specific recombinases, especially SpoIVCA, strongly suggested to us that xis $F$ encoded the recombinase for the $f d x N$ element. To determine whether $x i s F$ was sufficient to cause site-specific recombination of an artificial substrate molecule, an $E$. colibased rearrangement assay was designed. The approach was similar to that used for the identification of the xis $A$ gene on the nifD element (Lammers et al. 1986). A rearrangement substrate plasmid, pJG1A (Fig. 3A), was constructed by positioning a lac $Z$ gene between the restriction fragments An154.2 and An155 (Fig. 1), which contain the two $f d x N$ element recombination sites (Golden et al. 1987, 1988). Site-specific recombination between the directly repeated recombination sites will result in the deletion of the lac $Z$ gene from the plasmid and allow the rearrangement to be detected by the appearance of 


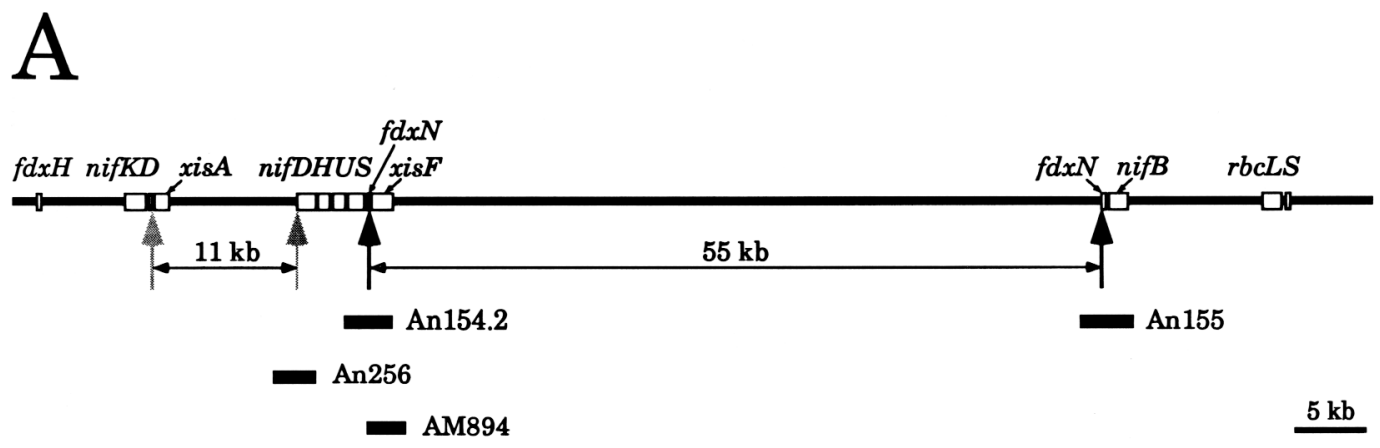

B

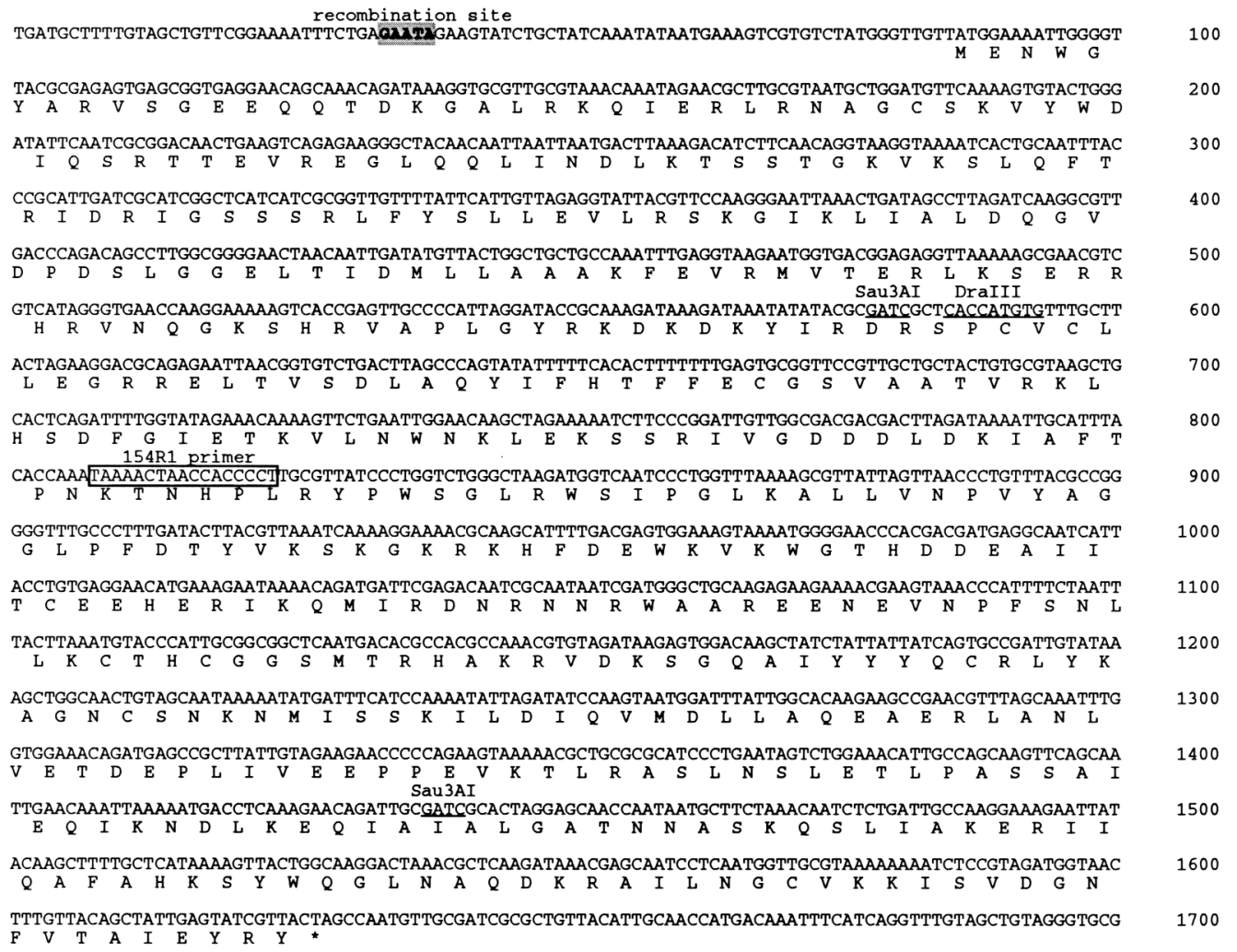

Figure 1. Map of the PCC 7120 chromosomal region containing the nifD and $f d x N$ elements, and the nucleotide sequence of $x i s F$. $(A)$ Map of the vegetative cell chromosomal region containing the nifD and $f d x N$ elements. The nifD element interrupts the nifHDK operon, which encodes the nitrogenase polypeptides. The $f d x N$ element interrupts the nifB-fdxN-nifS-nifU operon. The $f d x H$ gene encodes a heterocyst-specific ferredoxin, and the $r b c L S$ operon encodes the large and small subunits of ribulose-1,5-bisphosphate carboxylase. $x i s A$ and $x i s F$ encode the nif $D$ and $f d x N$ element site-specific recombinases, respectively. All genes read from right to left except for xisA, xisF, and $r b c L S$. The nifD and $f d x N$ recombination sites are indicated by gray and black arrows, respectively. The positions of subcloned DNA fragments used in this study are shown below the map. $(B \mid$ Nucleotide and predicted amino acid sequence of $x i s F$. The nifS-proximal recombination site of the $f d x N$ element is marked with a gray box; sequences to the left are from the $f d x N$ open reading frame. The DraIII site (underlined) and the 154R1 internal PCR primer (open box marks the complementary sequence) were used in plasmid constructions for the expression of xisF. The two Sau3AI sites (underlined) mark the internal fragment used to inactivate the xisF gene. The GenBank accession number for the sequence reported in this paper is L23220.

white colonies on X-gal indicator plates. DNA fragments to be tested for the production of recombinase are introduced on a compatible expression vector into $E$. coli har- boring pJGlA, and cells containing both plasmids are plated onto indicator plates.

Expression of $x i s F$ in $E$. coli caused the rearrangement 


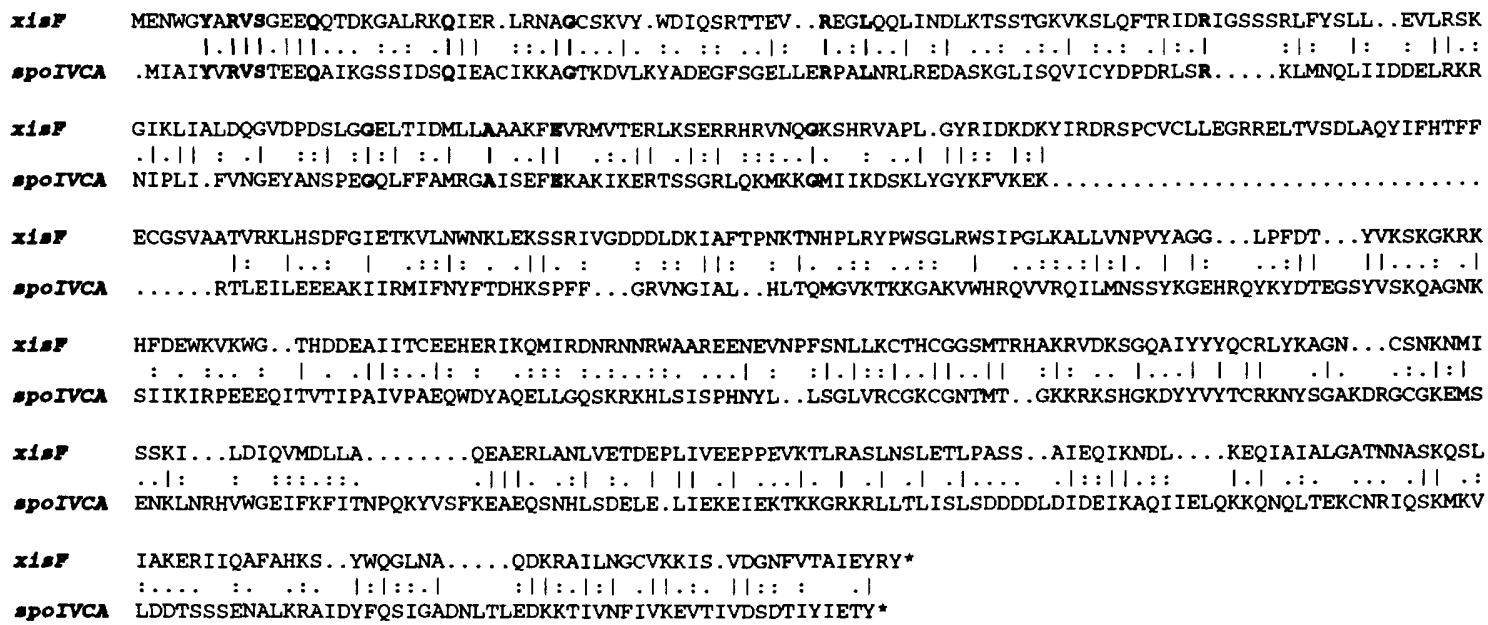

Figure 2. Comparison of the predicted XisF and the SpoIVCA proteins. The amino acid sequences of PCC 7120 XisF (515 amino acids) and $B$. subtilis SpoIVCA (500 amino acids) were aligned using the GAP program (default settings) from the GCG software package. The proteins showed $49 \%$ similarity and $27 \%$ identity over their entire length. The amino acids in bold are conserved among XisF, SpoIVCA, and the other site-specific recombinases in the resolvase family. Vertical lines indicate identical amino acids; $(:$.$) evolu-$ tionarily conserved amino acid substitutions.

of the pJGlA substrate plasmid. Figure $4 \mathrm{~A}$ shows a schematic representation of xisF-containing fragments cloned into the $E$. coli expression vector pSE380 (Brosius 1989). The plasmid pAM894 was constructed with a HaeII-Xbal fragment from pAnl54 (Golden et al. 1988), which contains the Xis $F$ open reading frame and $375 \mathrm{bp}$ of upstream sequence and $1 \mathrm{~kb}$ of downstream sequence. Introduction of pAM894 into $E$. coli strain DH5 $\alpha \mathrm{MCR}$ containing pJG1A produced only blue colonies upon initial plating. However, liquid cultures inoculated from a single blue colony and incubated overnight produced a few white colonies $<0.1 \%$ of the total colonies) when plated onto X-gal indicator medium. Restriction analysis of the plasmids contained in most of these white colonies produced the pattern expected to result from sitespecific recombination (data not shown). We suspected
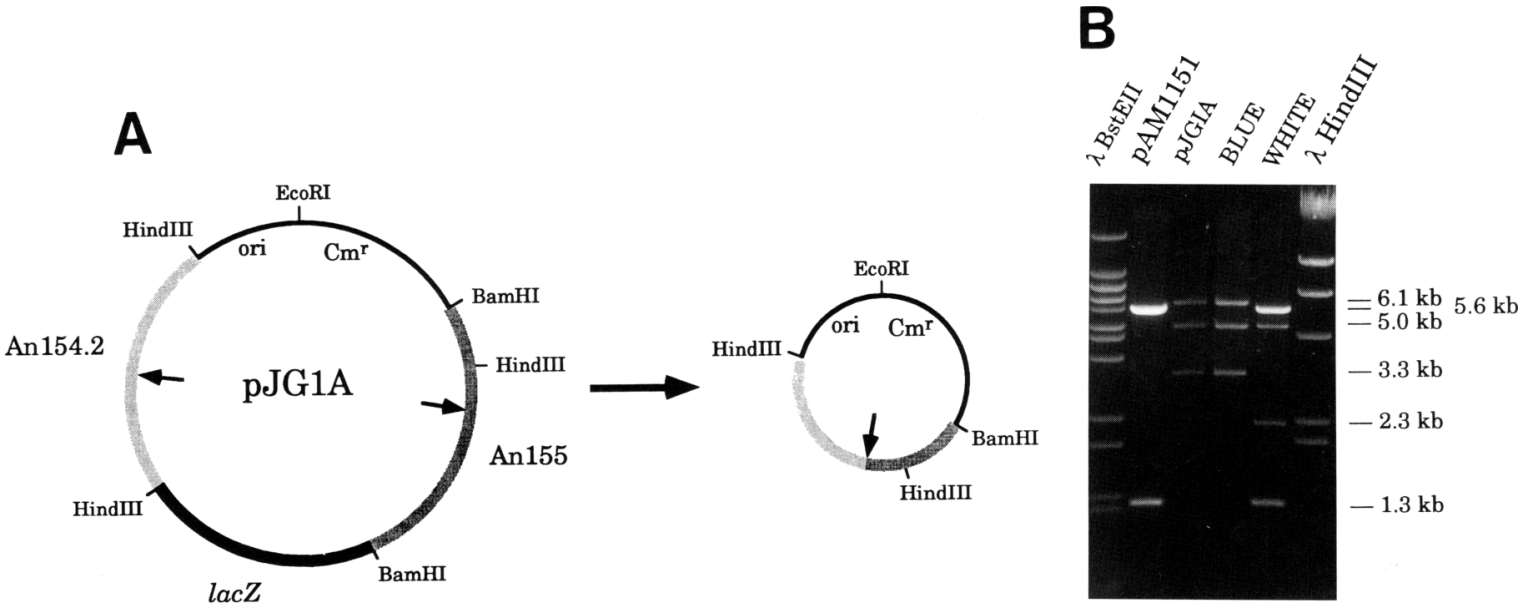

Figure 3. Site-specific recombination of pJG1A. (A) Map of pJG1A before and after excision of the lacZ gene. The HindIII fragment An154.2 contains the nifS-proximal $f d x N$ element recombination site. The EcoRI fragment An155 (converted to a BamHI fragment) contains the nifB-proximal recombination site. The thin line represents the vector pACYC184; the fragment containing lac $Z$ is shown as a thick black line. Arrows mark the recombination sites before and after rearrangement of the substrate plasmid. The excised fragment containing the lac $Z$ gene cannot replicate and is not shown. $(B)$ Rearrangement of pJG1A in $E$. coli. The rearrangement assay was carried out as described in Materials and methods. Plasmid DNA was prepared from overnight cultures started from blue or white colonies. The plasmid DNA was digested with the restriction enzyme HindIII and analyzed by electrophoresis on a $0.7 \%$ agarose gel containing ethidium bromide. (Lanes 1,6) $\lambda$ DNA digested with BstEII and HindIII, respectively, as size marker; (lane 2) xisF expression plasmid pAM1151 marker; (lane 3) pIG1A marker; (lane 4) plasmid from a blue colony showing unrearranged pJG1A (pAM1151 was lost; see text); (lane 5) plasmid from a white colony showing rearranged pJGlA (pAM1151 is also present). 


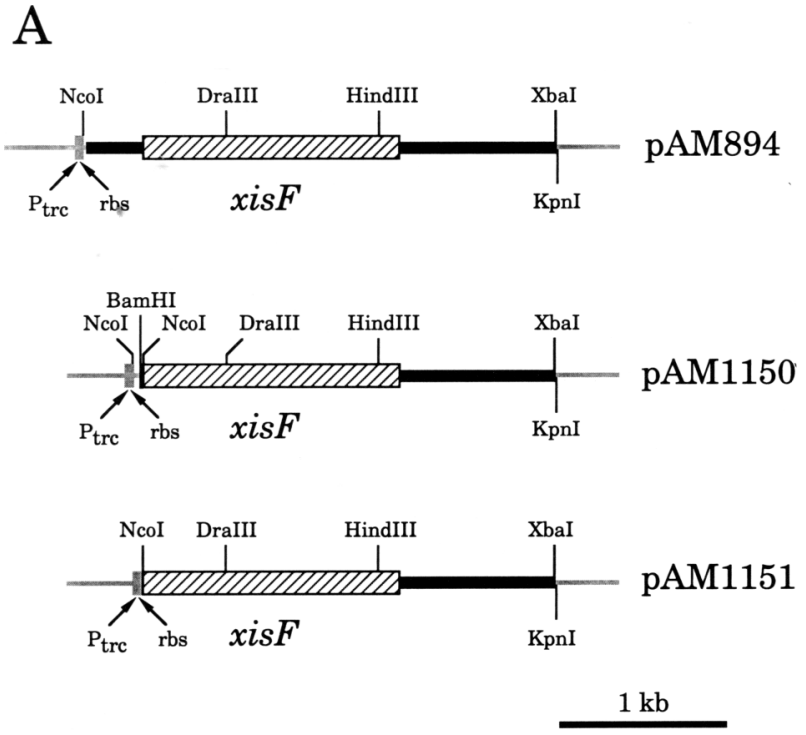

B

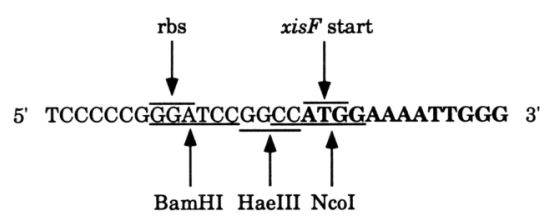

Figure 4. xisF expression plasmids. (A) The plasmid pAM894 contains the $x i s F$ gene on a $2.9-\mathrm{kb}$ restriction fragment cloned into the $E$. coli expression vector pSE380 (gray). The vector contains a $P_{t r c}$ promoter and a ribosome binding site (rbs) upstream from an NcoI site. The $2.9-\mathrm{kb}$ fragment contains a $1.54-\mathrm{kb}$ open reading frame (hatched box) with $375 \mathrm{bp}$ of upstream and $1 \mathrm{~kb}$ of downstream sequence. The plasmid pAM1150 was constructed by replacing the $5^{\prime}$ end of xisF with a synthetic fragment generated by PCR that lacks all upstream sequences. pAM1151 was derived from pAM1 150 by removing the 102-bp Ncol fragment. Expression of xisF from pAMl 151 utilizes the $P_{t r c}$ promoter and the ribosomal binding site on the pSE380 vector. $(B)$ xisF PCR primer. The primer used for amplification of the xisF $5^{\prime}$ end contained 13 bases of the XisF-coding region. The upstream sequence was designed to included BamHI, HaeIII, and NcoI restriction sites. The position of the BamHI site produced an imperfect ribosomal binding site. This PCR primer, along with the internal 154RI primer (Fig. 1), was used to amplify a fragment containing restriction sites that allowed the construction of pAM1150, pAM1151, and pAM1152.

that the low frequency of pJGlA rearrangement might be the result of inefficient xis $F$ expression in $E$. coli caused by the upstream sequences present in pAM 894 .

In an effort to increase the efficiency of $x i s F$ expression in E. coli, PCR was used to modify the $5^{\prime}$ end of the $x i s F$ gene. A DNA primer was designed to contain the first 13 bp of the $x i s F$ open reading frame and the restriction sites for BamHI, HaeIII, and NcoI (Fig. 4B). The BamHI site was positioned so that it could produce a partial ribosomal binding site. This $5^{\prime}$ primer and an internal xisF gene-specific primer were used to amplify a fragment containing the $x i s F 5^{\prime}$ region from a pAn154 template. The amplified product was cloned as a BamHI-DraIII fragment, along with a $D r a I I I-X b a I$ xisF fragment from pAM894, into pSE380 to produce pAM1150 (Fig. 4A). Removal of the small NcoI fragment from pAM1150 created pAM1151 (Fig. 4A), in which the xisF gene is correctly positioned to utilize the pSE380 promoter and ribosome binding site. pAM1150 and pAM1151 were tested for their ability to cause rearrangement of pJGlA. Strains containing either plasmid and pJGlA produced approximately $1 \%$ white colonies in overnight liquid cultures. The percentage of white colonies was quite variable because of the expected fluctuation when a cell was produced that contained only rearranged pJGlA during the growth of the culture. Although the rearrangement frequency was significantly higher than that obtained with the original pAM894 plasmid, the failure to obtain higher frequencies indicates that the conditions present in the $E$. coli assay are significantly different than those present in a differentiating heterocyst.

Figure $3 \mathrm{~B}$ shows the HindIII restriction pattern produced by pAM1151, pJG1A, and the plasmids isolated from a blue and a white colony in the rearrangement assay. The pJG1A plasmid contains three HindIII restriction enzyme sites that produce fragments of 6.1, 5.0, and $3.3 \mathrm{~kb}$. Rearrangement of pJGlA removes one HindIII site and results in two fragments of 5.0 and $2.3 \mathrm{~kb}$. DNA sequence analysis of a rearranged plasmid confirmed that it was generated by site-specific recombination between the directly repeated sequences present at the borders of the $f d x N$ element (data not shown). Control experiments with pJG1A alone or in the presence of the pSE380 vector produced a few rare white colonies, but none of these contained plasmids that showed a restriction pattern consistent with site-specific recombination.

We found that a few of the $E$. coli cultures started from either blue or white colonies had lost the xisF-containing plasmid. For example, the plasmid sample from the blue colony shown in Figure 3B contains pJGlA but does not contain the 5.6- and 1.3-kb HindIII fragments of pAM1151 that are present in the plasmid sample from the white colony. The loss of these ampicillin-resistant $\left(A p^{r}\right)$ plasmids is possible because of the destruction of the antibiotic relatively early during the growth of the culture. Loss of the xisF-containing plasmids suggests that overexpression of XisF causes plasmid instability, an effect presumably related to its recombinase activity. This phenomenon was not studied further; however, a similar effect was observed with xisA (Lammers et al. 1986).

\section{Inactivation of xisF in PCC 7120}

To determine whether $x i s F$ is required for rearrangement of the $f d x N$ element during heterocyst differentiation, we inactivated the XisF gene in the PCC 7120 chromosome. An 864-bp Sau3AI fragment internal to the xis $F$ open reading frame was cloned into the vector pAM580 to create pAM882 (Fig. 5). The Sau3AI fragment lacks $492 \mathrm{bp}$ from the $5^{\prime}$ end of $x i s F$ and $189 \mathrm{bp}$ from the $3^{\prime}$ end. 


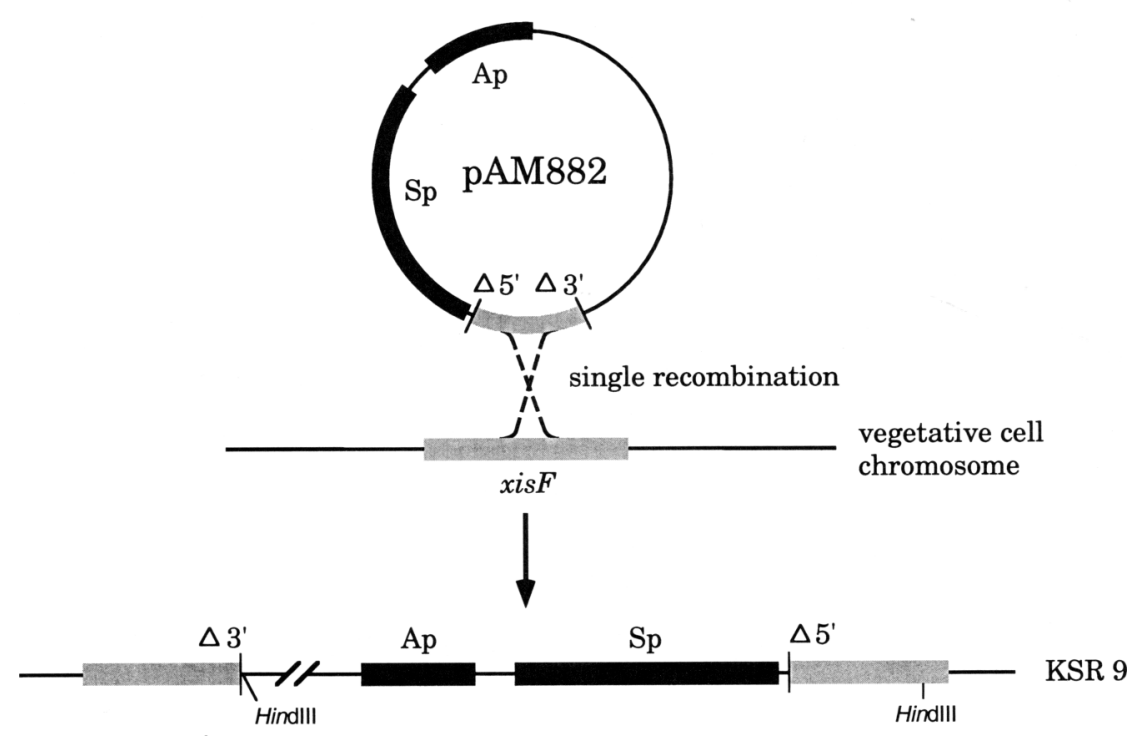

Figure 5. Inactivation of xisF in the strain KSR9. The plasmid pAM882 contains an internal 864-bp fragment of xisF (gray bar) cloned into the conjugal vector pAM580. The $x i s F$ fragment is missing 492 bp of $5^{\prime}$ sequence $\left(\Delta 5^{\prime}\right)$ and 189 bp of $3^{\prime}$ sequence $\left(\Delta 3^{\prime}\right)$. A single homologous recombination event between pAM882 and the xisF gene on the PCC 7120 chromosome results in integration of the plasmid into the chromosome and creation of two incomplete copies of the xisF gene. The HindIII sites that produce a 6.9 -kb fragment in KSR9 are shown. (Ap) Ampicillin resistance gene; $(\mathrm{Sp})$ spectinomycin resistance gene.
pAM882 was transferred into PCC 7120 by conjugation and exconjugants resistant to streptomycin $(\mathrm{Sm})$ and spectinomycin $(\mathrm{Sp})$ were obtained. Because the vector is unable to replicate in the cyanobacterial cells, these exconjugants were expected to contain pAM882 integrated into the chromosome by a single homologous recombination event (Fig. 5). The recombination event results in two incomplete copies of the xisF gene, thereby inactivating the gene. Southern blot analysis confirmed the integration of pAM882 into the xisF gene, and one isolate, KSR9, was selected for further study (data not shown).

KSR9 grew normally on medium containing nitrate, but it was unable to sustain growth in the absence of a source of combined nitrogen. KSR9 produced heterocysts that appeared morphologically normal by light micros- copy and showed nearly normal heterocyst frequency and pattern formation. These characteristics are consistent with a defect in the excision of the $f d x N$ element

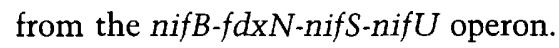

Southern analysis of DNA isolated from KSR9 vegetative cells and heterocysts showed that inactivation of the $x i s F$ gene prevented excision of the $f d x N$ element but did not affect excision of the nifD element. Figure 6 shows the Southern analysis of HindIII-digested DNA isolated from vegetative cells and heterocysts of wild-type PCC 7120, KSR9, and KSR11. Strain KSR11 is KSR9 complemented with an $x i s F$ gene on a shuttle vector (see below). The blots were probed with DNA fragments that contain the recombination sites for the $f d x N$ and nifD elements (for probe locations, see Fig. 1A). The HindIII fragment An154.2, which contains the nifS-proximal recombina-
An154.2

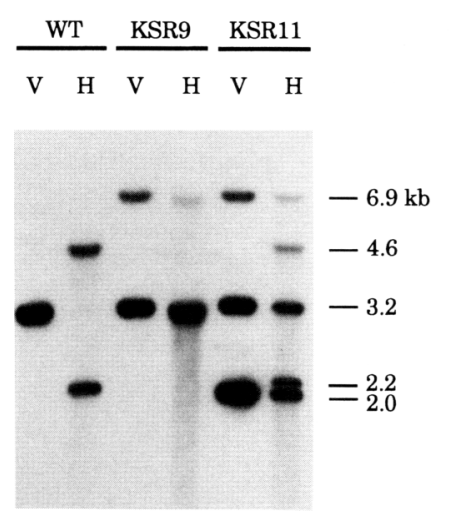

An155
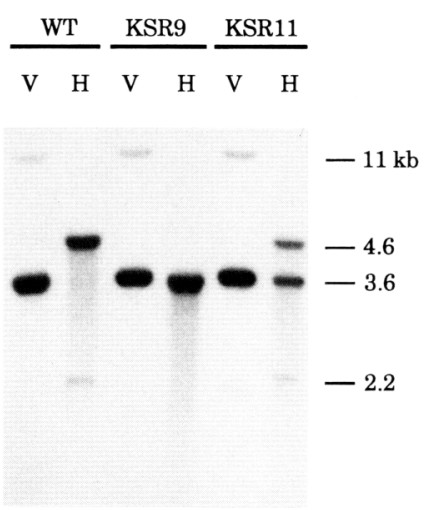

An256
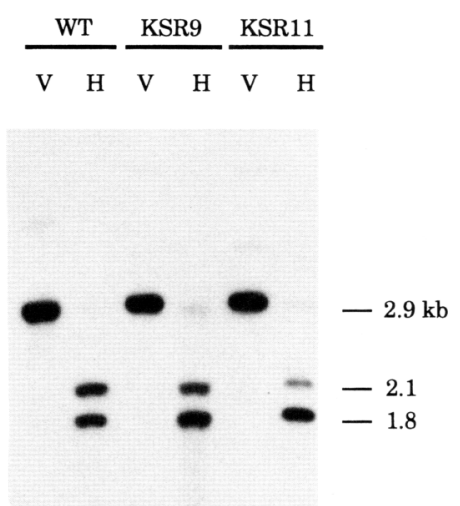

Figure 6. Rearrangement of the $f d x N$ and nifD elements in KSR9 and KSR11. Southern analyses of HindIII-digested DNA isolated from wild-type PCC 7120 (WT), KSR9, and KSR11 vegetative cells (V) and heterocysts (H). The DNA samples were fractionated by electrophoresis on a $0.7 \%$ agarose gel and then transferred to a nylon membrane. The blot was hybridized with radiolabeled probes generated from restriction fragments An 154.2 and An155, which span the $f d x N$-element recombination sites, and An256, which spans one of the nifD-element recombination sites (see Fig. 1). 
tion site of the $f d x N$ element, hybridized with itself at $3.2 \mathrm{~kb}$ in wild-type vegetative cell DNA and with 4.6and 2.2-kb fragments in heterocyst DNA, which are the products of rearrangement. KSR9 vegetative cell DNA showed 3.2- and 6.9-kb fragments with the An154.2 probe because of the integration of pAM882. The KSR9 heterocyst DNA showed no sign of rearrangement with the An154.2 probe. The EcoRI fragment An155, which contains the nifB-proximal recombination site, hybridized with a 3.6-kb HindIII fragment in wild-type vegetative cell DNA and with 4.6- and 2.2-kb fragments in heterocyst DNA. A faint 11-kb HindIII fragment, An265 (Golden et al. 1987), also hybridized with this probe. The KSR9 heterocyst DNA showed no sign of rearrangement with the An155 probe. The larger 6.9- and 11-kb fragments described above are underrepresented in the heterocyst DNA samples because of partial degradation of the DNA that occurs during the isolation procedure.

The Southern blots were also probed with the HindIII fragment An256, which contains the nifH-proximal recombination site of the nifD element, to determine whether the nifD element is excised normally in KSR9 (Fig. 6). Wild-type PCC 7120 vegetative cellular DNA showed hybridization to the $2.9-\mathrm{kb}$ An256 fragment, and heterocyst DNA showed 2.1- and 1.8-kb fragments characteristic of the rearranged nifD element. DNA from KSR9 vegetative cells and heterocysts showed the same pattern as the wild type. These results show that the nif $D$ rearrangement is not affected by inactivation of the xisF gene.

\section{Expression of xisF in KSR9 and PCC 7120}

The xis $F$ gene was cloned into a conjugal expression vector to accomplish two goals. One was to complement the xisF mutation in KSR9 to confirm that the phenotype of KSR9 was attributable to the inactivation of xisF. The other was to determine whether forced expression of $x i s F$ in vegetative cells would cause excision of the $f d x N$ element. The shuttle vector pAM692 contains the PCC $7120 \mathrm{rbcL}$ and $g \ln A$ promoters in tandem upstream of a cloning site (T.S. Ramasubramanian, unpubl.). The $r b c L$ and $g \ln A$ promoters both drive transcription in vegetative cells while the $g \ln A$ promoter also allows for expression of genes in heterocysts (Tumer et al. 1983; Nierzwicki-Bauer et al. 1984|. The xisF gene from pAM1 150 (Fig. 4A) was cloned as a BamHI-KpnI fragment into the same unique restriction sites of pAM692 creating pAM1152. pAM1152 was transferred by conjugation into the strain KSR9, creating strain KSR11, and into wild-type PCC 7120 , creating strain 692 xisF.

Southern blot analysis of KSR 11 is shown in Figure 6. The An154.2 and An155 probes showed that the xisF gene in pAM1152 was able to complement the xis $F$ mutation in KSR9. Both probes showed the presence of DNA fragments produced by the excision of the $f d x N$ element. However, the KSR11 heterocyst DNA also showed significant amounts of unrearranged $f d x N$ element, indicating that the xisF gene on pAM1 152 was not able to fully complement the inactivated gene in the chromosome. The 2.0-kb fragment identified with the An154.2 probe in KSR11 DNA represents the xisF gene in pAM1152. The An 256 probe showed the same pattern of bands for KSR11 as for the wild type and KSR9, indicating that $X i s F$ had no influence on the rearrangement of the nifD element.

Expression of xisF in vegetative cells is not sufficient to cause excision of the $f d x N$ element. The vector pAM692 can provide very high levels of expression of a lacZ reporter gene in PCC 7120 vegetative cells (T.S. Ramasubramanian, unpubl.\}. The plasmid pAM1152 should express xisF in vegetative cells, and Northern analysis of RNA isolated from wild-type cells harboring pAM1 152 confirmed that XisF message was present in significant amounts (data not shown). However, Southern analysis of this strain showed no detectable rearrangement of the $f d x N$ element in vegetative cells (data not shown). KSR11, which contains pAM1152, also showed no rearrangement of the element in vegetative cells with either the An154.2 or An155 probe (Fig. 6).

\section{Discussion}

The Anabaena sp. strain PCC 7120 xis $F$ gene encodes a developmentally regulated site-specific recombinase required for excision of the $f d x N$ element from the chromosome during heterocyst differentiation. Expression of $x i s F$ was sufficient to cause site-specific recombination of an artificial substrate in E. coli, and inactivation of $x i s F$ in PCC 7120 prevented rearrangement of the $f d x N$ element in heterocysts. A plasmid-borne copy of xis $F$ transcribed by a heterologous promoter complemented the $x i s F$ mutation but failed to force rearrangement of the $f d x N$ element in vegetative cells. XisF shows significant sequence similarity to the developmentally regulated SpoIVCA recombinase from $B$. subtilis and to the resolvase family of site-specific recombinases.

The xisF mutant KSR9 fails to excise the $f d x N$ element from the chromosome and cannot grow on media lacking a source of combined nitrogen; however, it forms morphologically normal heterocysts. These results mirror those obtained with xisA (Golden and Wiest 1988) and suggest that the $f d x N$ element must be precisely excised from the chromosome to allow the correct expression of the nifB-fdxN-nifS-nifU operon. Although the xisF mutant shows that excision of the $f d x N$ element is required to produce a functional heterocyst, no positive role for the element has been identified in vegetative cells or heterocysts. xis $F$ is the only gene that has been identified on the $f d x N$ element, and no region of the element shows detectable levels of transcription in either vegetative cells or heterocysts (Golden et al. 1988).

XisF may not be completely sufficient for site-specific recombination. Expression of $x i s F$ in $E$. coli from a strong promoter in the plasmids pAM894, pAM1150, and pAM1151 caused site-specific recombination and rearrangement of the PJG1A substrate but only at a low frequency.

Similarly, expression of xisF from the plasmid pAM1152 complemented the xisF mutation in KSR9 
heterocysts but failed to rearrange the $f d x N$ element in vegetative cells of KSR9 or wild-type PCC 7120 . Although several trivial explanations could account for these results, we suspect that at least one accessory factor, which is not present in E. coli or PCC 7120 vegetative cells, may be required for efficient recombination. The accessory factor could act similarly to IHF or FIS by participating in the assembly of a higher-order nucleoprotein complex required for efficient recombination (Landy 1989; Finkel and Johnson 1992). If the accessory factor were heterocyst specific, then rearrangement would occur inefficiently in E. coli or PCC 7120 vegetative cells even when xisF was overexpressed.

Expression of $x i s F$ from the plasmid pAM1 152 caused excision of only about half of the $f d x N$ elements in KSR 9 heterocysts. This incomplete complementation may indicate that the XisF protein does not diffuse through the cell efficiently; the resolvase family of proteins tend to be hydrophobic and form insoluble inactive aggregates when overproduced (Glasgow et al. 1989; Sherratt 1989). Alternatively, the insertional inactivation of the xis $F$ gene in KSR9 may have a polar effect on the expression of downstream genes that might be required for efficient rearrangement.

The mechanism for heterocyst-specific regulation of the $f d x N$ element excision is not known. In Bacillus, excision of the skin element requires the spoIIID gene, which encodes a mother cell-specific transcription factor (Kunkel et al. 1989). Our understanding of cell-type specificity for the Anabaena nifD and $f d x N$ elements will require the identification of genes like spoIIID by use of genetic or biochemical approaches.

The Anabaena $f d x N$ element and the Bacillus skin element have several similar features. The amino acid sequence similarity between their recombinases, XisF and SpoIVCA, respectively, indicates that the elements are evolutionarily related. Both elements are relatively large, 55 and $42 \mathrm{~kb}$, respectively, and could encode a substantial number of genes. They both excise from the chromosome by conservative site-specific recombination that restores the coding sequences within which the elements reside. The genes that are interrupted by the elements are not required for vegetative growth, but they are required in the terminally differentiated cell type that undergoes rearrangement, the sigK gene in Bacillus mother cells, and the nifB-fdxN-nifS-nifU operon in $A n$ $a b a e n a$ heterocysts. For both elements, failure to excise from the chromosome results in a nonfunctional cell. It will be interesting if other similarities exist between the Bacillus and Anabaena elements. For example, in neither case is it known what selective pressures might be provided by these elements that allows them to be maintained in their hosts.

\section{Materials and methods \\ Strains and growth conditions}

Anabaena sp. strain PCC 7120 and derived strains were grown as described except that some large-scale liquid cultures were grown in BG-11 medium instead of AA/8 medium (Golden et al. 1991). Heterocyst induction and isolation were essentially as described with minor modifications (Golden et al. 1991). Heterocysts were purified away from vegetative cells by passing the filaments through a Stansted cell disruptor at 12,000 psi. This procedure produces complete breakage of vegetative cells while leaving most of the heterocysts intact.

E. coli strains $\mathrm{HB} 101, \mathrm{DH} 5 \alpha \mathrm{MCR}$, and $\mathrm{DH} 10 \mathrm{~B}$ were used for plasmid maintenance and cyanobacterial conjugations and were grown in LB or $0.5 \times \mathrm{TB}$ medium with appropriate antibiotics as described (Golden et al. 1991).

\section{DNA manipulations}

DNA manipulations and recombinant DNA techniques were performed by standard procedures (Ausubel et al. 1987). Plasmid DNA was isolated from E. coli essentially as described in the Geneclean Kit (Bio 101). PCC 7120 vegetative cell and heterocyst DNA was isolated as described (Golden et al. 1991). Restriction endonucleases and other DNA-modifying enzymes were used according to the manufacturer's recommendations or standard protocols. For Southern analysis, DNA was transferred from agarose gels to MagnaCharge membranes (MSI) with 50 $\mathrm{mm} \mathrm{NaOH}, 1 \mathrm{M} \mathrm{NaCl}$. DNA probes were labeled using a random primer kit (Boehringer Mannheim), and Southern hybridizations were performed as described (Golden et al. 1991).

\section{DNA sequencing}

Double-stranded DNA sequencing was done using the Sequenase II sequencing kit (U.S. Biochemical) and $\left[\alpha-{ }^{32} \mathrm{P}\right] \mathrm{dATP}$ (DuPont, NEN Research Products). Sequencing reactions were primed with custom-made oligonucleotides. Sequencing data were analyzed using the sequence analysis software package of the Genetics Computer Group (GCG) (Devereux et al. 1984) and the NCBI GenBank BLAST e-mail server (Altschul et al. 1990).

\section{PCR}

PCR reactions were carried out in a MiniCycler (MJ Research) with Taq polymerase (U.S. Biochemical) under the following conditions-denaturation at $94^{\circ} \mathrm{C}$ for $1 \mathrm{~min}$; annealing at $40^{\circ} \mathrm{C}$ for $2 \mathrm{~min}$; polymerization at $72^{\circ} \mathrm{C}$ for $3 \mathrm{~min}$-and cycled 30 times. The $x i s F$ internal primer sequence is identified in Figure 1 , and the $5^{\prime}$ primer is shown in Figure 4. The cloned PCR product was confirmed by DNA sequencing.

\section{Plasmid constructions}

The xisF open reading frame was cloned as a HaeII (blunted)$X b a$ I fragment from pAn 154 into the SmaI and $X b a I$ sites of pSE380 to produce pAM894. The plasmid pAM1150 was constructed with a synthetic xisF $5^{\prime}$ end produced by PCR. The primers used for the PCR were an internal 154Rl primer (Fig. 1) and a 5' primer (Fig. 4) that had all upstream sequences replaced with appropriate cloning sites. The PCR product was digested with BamHI and DraIII and ligated along with the DraIII-XbaI fragment from pAM894 into the BamHI and XbaI sites of pSE380. For shuttle vector constructions, the xisF gene was obtained from pAM 1150 as a BamHI-KpnI fragment. The xisF gene was placed under the control of the $P_{\text {trc }}$ promoter and ribosome binding site of pSE380 by removing the 102-bp NcoI fragment from pAM1150 to produce pAM1151.

The plasmid pAM882 was used to inactivate the xis $F$ gene in the PCC 7120 chromosome. A xisF internal 864-bp Sau3AI fragment (Fig. 1) was cloned into one of the two BamHI sites of 
pAM580 to make pAM882. pAM580 was constructed by inserting a $\mathrm{Sp}^{\mathrm{r}} / \mathrm{Sm}^{\mathrm{r}} \Omega$ cassette into the BamHI (partial) and HindIII sites of the conjugal suicide vector pDW6 (Golden et al. 1991).

The xis $F$ gene was cloned into the shuttle vector pAM692 (T.S. Ramasubramanian, unpubl.) for expression in vegetative cells and heterocysts. The plasmid pAM1152 was constructed by ligating a BamHI-KpnI fragment released from pAM1150 into the corresponding sites of pAM692.

The rearrangement substrate plasmid pJG1A was constructed by placing a lac $Z$ gene between the $f d x N$ element recombination sites. A BamHI-HindIII fragment containing the lacZ gene from pDX11-1871 (M. Benedik, unpubl.) was cloned into the same sites of pACYC184 to make pACYClac [chloramphenicol resistant $\left.\left(\mathrm{Cm}^{\mathrm{r}}\right)\right]$. The 3.2-kb HindIII fragment An 154.2 (Fig. 1) was cloned into the HindIII site of pACYClac to obtain pACYClac154.2A, which has lacZ on the $f d x N$-element side of An154.2. The 3.5-kb EcoRI fragment Anl55 (Fig. 1) was cloned into the EcoRI site of pUC1819RI and then released as a BamHI fragment. pUC1819RI was constructed by ligating the large ScaI-EcoRI fragment from pUC18 to the small ScaI-EcoRI fragment from pUC19 producing a unique $E c o R I$ site flanked by an inverted repeat of the multiple cloning site. The An155 BamHI fragment was cloned into the $B a m H I$ site of pACYClac154.2A to make pJGlA, which has $l a c Z$ on the $f d x N$-element side of An155.

\section{Strain constructions}

Conjugation of shuttle vectors and the pAM882 suicide vector into PCC 7120 were performed essentially as described except for minor modifications (Golden and Wiest 1988). The E. coli donor strain was AM512, which is DH5 $\alpha$ MCR containing the plasmids pRL528 and pRL443 (Elhai and Wolk 1988). The strain KSR9 was constructed by the integration of pAM 882 into the xisF gene on the PCC 7120 chromosome by homologous recombination. Filaments from a growing $100-\mathrm{ml}$ PCC 7120 culture were collected by centrifugation and suspended in $4.5 \mathrm{ml}$ of BG-11. Cells from a 5-ml overnight culture of AM512 containing pAM 882 were collected by centrifugation, washed once to remove antibiotics, and suspended in $1 \mathrm{ml}$ of $L B$ medium. The PCC 7120 cells were mixed with $500 \mu$ l of the $E$. coli donor cells and incubated overnight without shaking in a $50-\mathrm{ml}$ flask at $30^{\circ} \mathrm{C}$ with $150 \mu \mathrm{E} / \mathrm{m}^{2}$ per sec light intensity. The filaments were collected by centrifugation and evenly distributed among five $90-\mathrm{mm}$ petri plates containing $40 \mathrm{ml}$ of BG-11 agar medium supplemented with $\mathrm{Sm}(2 \mu \mathrm{g} / \mathrm{ml})$ and $\mathrm{Sp}(2 \mu \mathrm{g} / \mathrm{ml})$. The plates were incubated at $30^{\circ} \mathrm{C}$ with $150 \mu \mathrm{E} / \mathrm{m}^{2}$ light intensity; exconjugant colonies appeared in 10-14 days. Two exconjugant colonies from independent conjugations were analyzed by Southern hybridization to confirm that they were the result of a single recombination event that integrated pAM882 into the chromosome. One clone, KSR9, was select for further analysis.

The strains $692 x i s F$ and KSR 11 were constructed by conjugating pAM1152 into PCC 7120 and KSR9, respectively. An overnight culture $(1.5 \mathrm{ml})$ of the $E$. coli donor was pelleted and resuspended in the original volume of LB medium. Filaments from $1.5 \mathrm{ml}$ of a growing culture of the PCC 7120 recipient were collected by centrifugation and resuspended in $1 \mathrm{ml}$ of BG-11. Washed donor cells $(100 \mu \mathrm{l})$ were added to the recipient filaments in a $1.5 \mathrm{ml}$ microcentrifugation tube, pelleted, and resuspended with BG-11 to $\sim 90 \mu \mathrm{l}$. LB $(10 \mu \mathrm{l})$ was added, and the cells were incubated overnight as above. Exconjugants were selected on BG-11 agar petri plates containing neomycin $(\mathrm{Nm})(25 \mu \mathrm{g} /$ $\mathrm{ml})$ for the PCC 7120 recipient or neomycin $(15 \mu \mathrm{g} / \mathrm{ml}), \mathrm{Sp}(2$ $\mu \mathrm{g} / \mathrm{ml})$, and $\mathrm{Sm}(2 \mu \mathrm{g} / \mathrm{ml})$ for KSR9. The presence of pAM1152 was confirmed by Southern analysis.

\section{Rearrangement assay}

The rearrangement assay was based on the loss of lac $Z$ from pJGlA by site-specific recombination in $E$. coli. Essentially, $E$. coli cells harboring pJGlA and a compatible expression vector containing a DNA fragment to be tested for the $f d x N$-element recombinase gene were grown overnight and plated onto indicator plates to detect loss of the $l a c Z$ gene from the plasmid. xisF expression plasmid pAM894, pAM1150, or pAM1151, along with the rearrangement substrate pJG1A, was introduced into DH5 $\alpha$ MCR cells by electroporation and plated onto LB medium containing Ap, $\mathrm{Cm}$, and 5-bromo-4-chloro-3-indolyl- $\beta$ D-galactoside (X-gal). Two independent blue colonies were each used to inoculate two $5-\mathrm{ml}$ cultures of LB medium supplemented with $\mathrm{Ap}$ and $\mathrm{Cm}$. One culture was supplemented with $1 \mathrm{~mm}$ isopropyl- $\beta$-D-thiogalactoside (IPTG). After growth at $37^{\circ} \mathrm{C}$ for 24 and $48 \mathrm{hr}, 25 \mu \mathrm{l}$ of a $10^{-3}$ dilution of each culture was plated onto LB agar containing IPTG, X-gal, Ap, and Cm. White colonies were selected for restriction analysis of the pJG1A plasmid. In several experiments a sample was also plated onto LB agar containing $\mathrm{Cm}$ alone to estimate the frequency of loss of the xisF expression plasmid.

\section{Acknowledgments}

This work was supported by the U.S. Public Health Service (grant GM36890) from the National Institutes of Health and National Science Foundation (grant DMB-8553185).

The publication costs of this article were defrayed in part by payment of page charges. This article must therefore be hereby marked "advertisement" in accordance with 18 USC section 1734 solely to indicate this fact.

\section{References}

Altschul, S.F., W. Gish, W. Miller, E.W. Myers, and D.J. Lipman. 1990. Basic local alignment search tool. $/$. Mol. Biol. 215: 403-410.

Ausubel, F.M., R. Brent, R.E. Kingston, D.D. Moore, J.G. Seidman, J.A. Smith, and K. Struhl. 1987. Current protocols in molecular biology. Greene Publishing Associates/Wiley-Interscience, New York.

Brosius, J. 1989. Superpolylinkers in cloning and expression vectors. DNA 8: 759-777.

Brusca, J.S., C.J. Chastain, and J.W. Golden. 1990. Expression of the Anabaena sp. strain PCC 7120 xisA gene from a heterologous promoter results in excision of the nifD element. $J$. Bacteriol. 172: 3925-3931.

Devereux, J., P. Haeberli, and O. Smithies. 1984. A comprehensive set of sequence analysis programs for the VAX. Nucleic Acids Res. 12: 387-395.

Elhai, J. and C.P. Wolk. 1988. Conjugal transfer of DNA to cyanobacteria. Methods Enzymol. 167: 747-754.

Finkel, S.E. and R.C. Johnson. 1992. The Fis protein: It's not just for DNA inversion anymore. Mol. Microbiol. 6: 3257-3265.

Gellert, M. 1992. V(D)J recombination gets a break. Trends Genet. 8: 408-412.

Glasgow, A.C., K.T. Hughes, and M.I. Simon. 1989. Bacterial DNA inversion systems. In Mobile DNA (ed. D.E. Berg and M.M. Howe), pp. 637-659. American Society for Microbiology, Washington, D.C.

Golden, J.W. and D.R. Wiest. 1988. Genome rearrangement and nitrogen fixation in Anabaena blocked by inactivation of xisA gene. Science 242: 1421-1423.

Golden, J.W., S.J. Robinson, and R. Haselkorn. 1985. Rearrange- 
ment of nitrogen fixation genes during heterocyst differentiation in the cyanobacterium Anabaena. Nature 314: 419423.

Golden, J.W., M.E. Mulligan, and R. Haselkorn. 1987. Different recombination site specificity of two developmentally regulated genome rearrangements. Nature 327: 526-529.

Golden, J.W., C.D. Carrasco, M.E. Mulligan, G.J. Schneider, and R. Haselkorn. 1988. Deletion of a 55-kilobase-pair DNA element from the chromosome during heterocyst differentiation of Anabaena sp. strain PCC 7120. I. Bacteriol. 170: 5034-5041.

Golden, J.W., L.L. Whorff, and D.R. Wiest. 1991. Independent regulation of nifHDK operon transcription and DNA rearrangement during heterocyst differentiation in the cyanobacterium Anabaena sp. strain PCC 7120. I. Bacteriol. 173: 7098-7105.

Haber, J.E. 1992. Mating-type gene switching in Saccharomyces cerevisiae. Trends Genet. 8: 446-452.

Haselkorn, R. 1992. Developmentally regulated gene rearrangements in prokaryotes. Annu. Rev. Genet. 26: 113-130.

Haselkorn, R., J.W. Golden, P.J. Lammers, and M.E. Mulligan. 1986. Developmental rearrangement of cyanobacterial nitrogen-fixation genes. Trends Genet. 2: 255-259.

Kunkel, B., L. Kroos, H. Poth, P. Youngman, and R. Losick. 1989. Temporal and spatial control of the mother-cell regulatory gene spoIIID of Bacillus subtilis. Genes \& Dev. 3: $1735-1744$.

Kunkel, B., R. Losick, and P. Stragier. 1990. The Bacillus subtilis gene for the development transcription factor sigma $\mathrm{K}$ is generated by excision of a dispensable DNA element containing a sporulation recombinase gene. Genes \& Dev. 4: 525-535.

Kuritz, T., A. Ernst, T.A. Black, and C.P. Wolk. 1993. Highresolution mapping of genetic loci of Anabaena PCC 7120 required for photosynthesis and nitrogen fixation. Mol. Microbiol. 8: 101-110.

Lammers, P.J., J.W. Golden, and R. Haselkorn. 1986. Identification and sequence of a gene required for a developmentally regulated DNA excision in Anabaena. Cell 44: 905-911.

Landy, A. 1989. Dynamic, structural, and regulatory aspects of lambda site-specific recombination. Annu. Rev. Biochem. 58: 913-949.

Mulligan, M.E. and R. Haselkorn. 1989. Nitrogen-fixation (nif) genes of the cyanobacterium Anabaena sp. strain PCC 7120: the nifB-fdxN-nifS-nifU operon. J. Biol. Chem. 264: 1920019207.

Mulligan, M.E., W.J. Buikema, and R. Haselkorn. 1988. Bacterial-type ferredoxin genes in the nitrogen fixation regions of the cyanobacterium Anabaena sp. strain PCC 7120 and Rhizobium meliloti. I. Bacteriol. 170: 4406-4410.

Nierzwicki-Bauer, S.A., S.E. Curtis, and R. Haselkorn. 1984. Cotranscription of genes encoding the small and large subunits of ribulose-1,5-bisphosphate carboxylase in the cyanobacterium Anabaena 7120. Proc. Natl. Acad. Sci. 81: 59615965.

Oettinger, M.A. 1992. Activation of V(D)J recombination by RAG1 and RAG2. Trends Genet. 8: 413-416.

Popham, D.L. and P. Stragier. 1992. Binding of the Bacillus sub. tilis spoIVCA product to the recombination sites of the element interrupting the sigma K-encoding gene. Proc. Natl. Acad. Sci. 89: 5991-5995.

Prescott, D.M. 1992. The unusual organization and processing of genomic DNA in hypotrichous ciliates. Trends Genet. 8: $439-445$.

Sato, T., Y. Samori, and Y. Kobayashi. 1990. The cisA cistron of Bacillus subtilis sporulation gene spoIVC encodes a protein homologous to a site-specific recombinase. I. Bacteriol. 172: 1092-1098.

Sherratt, D. 1989. Tn3 and related transposable elements: sitespecific recombination and transposition. In Mobile DNA (ed. D.E. Berg and M.M. Howe), pp. 163-184. American Society for Microbiology, Washington, D.C.

Stark, W.M., M.R. Boocock, and D.J. Sherratt. 1992. Catalysis by site-specific recombinases. Trends Genet. 8: 432-439.

Stragier, P., B. Kunkel, L. Kroos, and R. Losick. 1989. Chromosomal rearrangement generating a composite gene for a developmental transcription factor. Science 243: 507-512.

Tobler, H., A. Etter, and F. Muller. 1992. Chromatin diminution in nematode development. Trends Genet. 8: 427-432.

Tumer, N.E., S.J. Robinson, and R. Haselkorn. 1983. Different promoters for the Anabaena glutamine synthetase gene during growth using molecular or fixed nitrogen. Nature 306: 337-342.

Wolk, C.P. 1982. Heterocysts. In The biology of cyanobacteria (ed. N.G. Carr and B.A. Whitton), pp. 359-386. University of California Press, Berkeley, CA.

- 1989. Alternative models for the development of the pattern of spaced heterocysts in Anabaena (Cyanophyta). Plant Syst. Evol. 164: 27-31. 


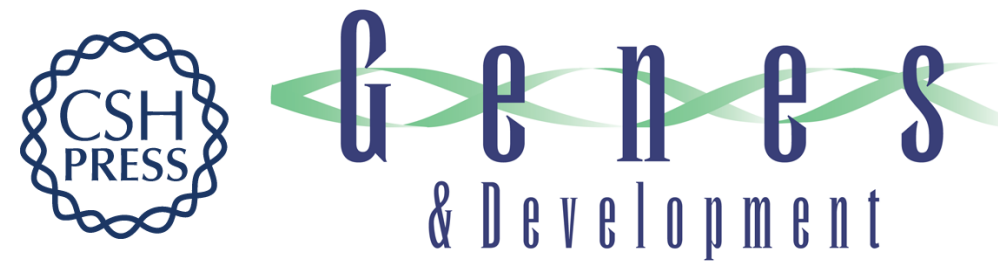

\section{Anabaena xisF gene encodes a developmentally regulated site-specific recombinase.}

C D Carrasco, K S Ramaswamy, T S Ramasubramanian, et al.

Genes Dev. 1994, 8:

Access the most recent version at doi:10.1101/gad.8.1.74

References This article cites 32 articles, 12 of which can be accessed free at:

http://genesdev.cshlp.org/content/8/1/74.full.html\#ref-list-1

License

Email Alerting

Service

Receive free email alerts when new articles cite this article - sign up in the box at the top right corner of the article or click here.

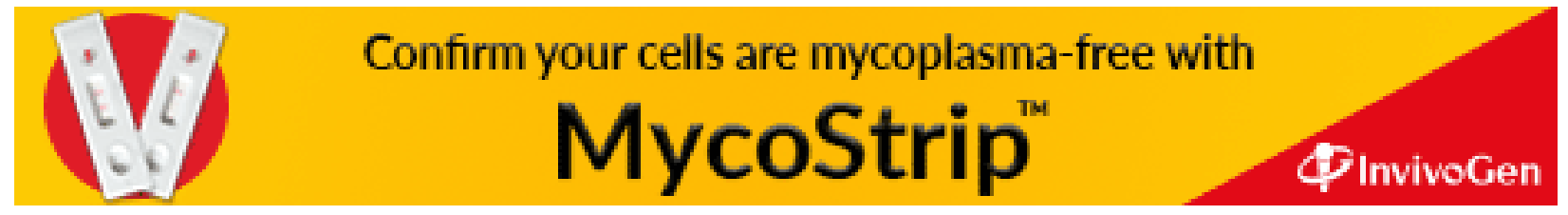

